\title{
Risk factor (predictive) medicine as a driver of fear and overdiagnosis
}

\section{Arnaud Chiolero senior lecturer in epidemiology}

Lausanne University Hospital, 1010 Lausanne, Switzerland

Heath is right to argue that we have to face up to our fears of uncertainty if we want to limit overdiagnosis and overtreatment. ${ }^{1}$ I think that one major driver of these fears comes from the development of medicine that is based on the identification and treatment of risk factors and from blurring of the boundaries between risk and disease. ${ }^{2}$ Indeed, being at risk of disease is increasingly confounded with having the disease itself. ${ }^{3}$ This is one reason why the diagnostic criteria for several conditions have been widened, thereby increasing the proportion of individuals who are potentially worried by their health. Admitting the limits of what risk factor (predictive) medicine can offer at an individual level could help prevent several of these problems. ${ }^{45}$

\section{Competing interests: None declared.}

Heath I. Role of fear in overdiagnosis and overtreatment-an essay by lona Heath. BM 2014;349:g6123. (24 October.)

2 Chiolero A, Paccaud F, Aujesky D, Santschi V, Rodondi N. How to prevent overdiagnosis. Swiss Med Wkly [forthcoming].

3 Aronowitz RA. The converged experience of risk and disease. Milbank Q2009:87:417-42. Ioannidis JPA. Genetic prediction for common diseases: will personal genomics ever work? Arch Intern Med 2012;172:744-6.

5 Davey-Smith G. Epidemiology, epigenetics and the "gloomy prospect": embracing randomness in population health research and practice. Int J Epidemiol 2011;40:537-62.

Cite this as: BMJ 2014;349:97078

() BMJ Publishing Group Ltd 2014 